\title{
Competences in On-Board Diagnostic Actuators for Effective Teaching of Petrol Engine Maintenance in Technical Colleges in Nigeria
}

\author{
${ }^{1}$ IGWE,N., ${ }^{2}$ Ikenwa, M. O. and ${ }^{3}$ Jwasshaka S. K. \\ ${ }^{1}$ Department of Industrial Technical Education, University of Nigeria, Nsukka \\ ${ }^{2}$ University of Nigeria Secondary School, Nsukka \\ ${ }^{3}$ School of Technical Education, Plateau State Polytechnic, Barkin Ladi
}

\begin{abstract}
The study aimed at determining the use of on-board diagnostic (OBD) actuators for effective teaching of Petrol Engine Maintenance (PEM) in technical colleges in Nigeria. Two research questions and a hypothesis guided the study. 5 OBD technicians and 58 teachers of Motor Vehicle Mechanics' Work (MVMW) responded to 14 item questionnaire to answer the research questions. The study was carried out in South Eastern States of Nigeria. The design for the study was the descriptive survey, using Borich's needs assessment model. Three experts face validated the contents of the instrument. Cronbach Alpha method was used to determine the reliability of the instrument which yielded a reliability of 0.93 . Mean and improvement need index (INI) were utilized to answer the research questions while the hypothesis was tested using Analysis of Variance (ANOVA). It was found that teachers of MVMW need improvement in on-board diagnostic actuators. Based on the findings, it was recommended that on-board diagnostic system should be integrated into the skills contents and learning contents of the curriculum of technical education programme.
\end{abstract}

\section{Introduction}

In the early seventies, the Environmental Protection Agency in the United States introduced a new policy that mandated the use of OBD for vehicles driven in the United States. This led to the development of new technologies that allowed mechanics and service technicians to monitor almost all aspects of vehicle performance on instruments hooked up to data ports on cars. OBD II replaced OBD I in the mid-nineties with more sophisticated monitoring systems and OBD III is on the horizon (Don, 2008).

OBD is a set of self-testing and diagnostic instructions programmed into the vehicle's on-board computer. The on-board computer is also referred to as Engine Control Unit (ECU). The programmes are specifically designed to detect failures in the sensors, actuators, switches and wiring of the various vehicle emissions-related systems. If the computer detects a failure in any of these components or systems, it lights an indicator on the dashboard to alert the driver. The indicator lights only when an emissions-related problem is detected (Smith, 2006). When the OBD system determines that a problem exists, a corresponding "Diagnostic Trouble Code" (DTC) is stored in the computer's memory and a special lamp on the dashboard called a Malfunction Indicator Lamp (MIL) is illuminated. This lamp is reserved for emissions problems only and cannot be used for other failures. (Automobiles use a variety of warning lamps to notify drivers of different conditions). In the case of an emissions MIL, either the phrase "Service Engine Soon" or "Check Engine" is used or an engine symbol is displayed. This light, usually yellow in colour, serves to inform the driver that a problem has been detected and vehicle service is needed (Nice, 2001). When the car is delivered to the repair shop, a service technician can quickly retrieve the stored DTCs from the computer memory of the vehicle. The stored DTCs will help the service technician diagnose and repair the problem. The actuators carry out the instructions from the ECU.

Actuators are devices, such as fuel injectors, ignition coils, camshaft actuator, throttle actuators which operate as outputs from the ECU. This means that they are normally electromechanical devices. A competent technician can achieve much in the field of diagnosis by knowing the type of electrical behaviour that is to be expected from tests on actuators that are in good condition and, if the test results are not as expected, the types of defect that may be causing an actuator to malfunction. Actuators normally rely on one of two electrical devices for their operation; they are either operated by a solenoid or by an electric motor. Solenoid-operated actuators are normally controlled in one of two ways. One is the duty cycle method, where the solenoid is switched on for a percentage of the time available, e.g. 20 or $80 \%$. This means that pulses of varying width can be used to provide the desired result. The other method of solenoid control is known as pulse width modulation (PWM). Here the solenoid current is switched on and off at frequencies that change to suit operating requirements. Electric motors that are used in actuators may be stepper motors, or reversible permanent magnet direct current motors. A stepper motor can be made to provide small movements of valves by temporary 
stopping the current supply. Some stepper motors take 48 steps for a full rotation. A common form of stepper motor uses two sets of windings. Current in one set of windings drives the motor shaft forward and when this is switched off and current is applied to the other set of windings, the motor shaft rotates in the reverse direction. This means that accurate control over the position of a valve can be achieved because the control computer determines the valve position by counting the number of pulses applied to the stepper motor windings (Nice, 2001). The importance of actuators in OBD system makes it imperative for its inclusion into the curriculum in technical colleges in Nigeria.

The curriculum for MVMW in the technical colleges is developed to offer a complete secondary school education in general education in addition to occupational areas while the central purpose of MVMW trade is to provide its recipient with the skill required for work in the automobile industry. Petrol Engine Maintenance (PEM) is one of the modules of MVMW. The goal of PEM is to produce a petrol engine maintenance craftsman who should understand the basic principles of operation and carry out general maintenance and reconditioning work on petrol engine. Some of the general objectives include that the trainee (student) should be able to: understand the basic working principles of petrol engine and restore it to peak performance, and understand the working principles of the fuel system of the motor vehicle (NBTE, 2009). In order to achieve these objectives, the students need to be taught using an innovative mechanism that can identify impending faults in the system for repair.

The teachers of Motor Vehicle Mechanics' Work should ensure that they continue to abreast themselves in the innovations of their field in order to remain relevant and effective. One of the ways they can ensure this is by updating their competencies through training and retraining while still teaching. This means that when a teacher is found deficient in either technical or professional skill or both, he/she needs enhancement to make up for identified inadequacies. The teachers of Motor Vehicle Mechanics' Work in Nigerian technical colleges should be competent in teaching Petrol Engine Maintenance to their students. Unfortunately, the situation is not the case in all technical colleges in Nigeria. One of the innovations of automobile technology is the use of on-board diagnostic system which has different components.

The improvement of OBD system is not affected by the experiences of the teachers. Motor Vehicle Mechanics' Work teacher, who is government employed, is employed by Ministry of Education. As a civil servant he/she has 35 years of service to put in his/her knowledge, skill and energy in teaching, provided he/she has not attain the age of 60 before the 35 years (Daily Trust, 2009). In the study, sixteen teachers of 0-5 years experience, eight teachers of 6-10 years experience, nine teachers of 11-15 years of experience, and six teachers of 16-20 years experience responded to the instrument. Others are seven teachers of 21-25 years experience, nine teachers of 26-30 years of experience and three teachers of 31-35 years experience. When the teacher, irrespective of his/her experience, improves on the OBD system, he/she becomes a competent teacher.

In the course specification, a teacher is expected to teach the components such as the sensors, actuators, computerized ignition system and diagnose faults using electronics equipment. Presently, the teachers teach these components distinctively. The teacher should be aware of the interrelatedness of these components. The interrelation of these components and few innovations in the component, in the emission system, is what is presently referred to as on-board diagnostic system (OBDS). Most of the teachers do not teach OBDS effectively, because they lack the competence to do so (Odigiri, 2004). The question here is what should be done by the teachers of Motor Vehicle Mechanics' Work in order to teach the Petrol Engine Maintenance so that when their students graduate they would be able to maintain these present manufactured vehicles which use onboard diagnostic system? It is therefore necessary to identify competency needs of the teachers of Motor Vehicle Mechanics' Work on the use of on-board diagnostic actuators for the teaching of Petrol Engine Maintenance in technical colleges.

In order to address the problem, the following research questions were formulated to guide the study:

- What are the competencies required by the teachers in the use of actuators of on-board diagnostic system for effective teaching of petrol engine maintenance?

- What are the improvement needs of the teachers in the use of actuators of on-board diagnostic system for effective teaching of petrol engine maintenance?

The technicians responded to research question 1, while the teachers responded to research question 2.

The following null hypothesis was formulated to guide the study and was tested at the .05 level of significance:

$\mathrm{Ho}_{1}$ : There is no significance difference in the mean ratings of the responses of the teachers of various years of teaching experiences in competences needed in on-board diagnostic actuators for effective teaching of Petrol Engine Maintenance in technical colleges in Nigeria.

\section{Methods}

The study adopted survey research and Borich needs assessment model. The Borich (1980) needs assessment model requires that a mean weighted discrepancy score be calculated for each item, competency or activity included in the needs assessment. A discrepancy can be calculated by comparing the participants' 
behaviors, skills, and competencies, with the goals of the program: "a discrepancy analysis that identifies the two polar positions of what is and what should be". Further, a comparison could be made to determine a group of individuals' perceived level of competence to complete a task, with their desired level of competence to complete a task.

In answering the research question, weighted mean and Improvement Needed Index (INI) was used, while analysis of variance (ANOVA) statistic was used to test the null hypothesis at 0.05 level of significance and appropriate degree of freedom. The mean was utilized in answering research question 1, while INI was utilised to analyse data on improvement needs of teachers of Motor Vehicle Mechanics' Work, which is research question 2. Any item with a mean rating of 3.50 and above is considered needed, while any item with a mean rating below 3.50 is regarded as not needed. This is because 3.50 is the lower real limit of 4.00 which represent averagely needed. The weighted mean of each item under the needed category was calculated (xn). The weighted mean of each item under the performance category was calculated (xp). The difference between the two means was calculated (xn-xp). This gave the value that indicated whether improvement is needed or not, and stated as follows:

(1) Where the difference is zero $(\mathrm{xn}-\mathrm{xp}=0)$ that is neutral, it indicates that there is no need for improvement on the item. However, for INI to be equal to zero, any of these conditions must occur:

(a) Very highly needed $=$ very high performance

(b) highly needed $\quad=\quad$ high performance

(c) averagely needed $\quad=\quad$ average performance

(d) Slightly needed = low performance and

(e) Not needed = very low performance

(2) Where the difference is positive $(\mathrm{xn}-\mathrm{xp}=+)$, it indicates that there is need for improvement of teachers on the item

(3) Where the difference is negative ( $\mathrm{xn}-\mathrm{xp}=-)$, it indicates that there is no need for improvement on the item because the mean performance $(\mathrm{xp})$ of the teachers for the scale is greater than the level at which that scale is needed (xn). That is, the teachers can perform the skill to the level at which it is needed and even above. (That is, INI=xn-xp. Where xn means needed and xp means performance) (Source: Olaitan and Ndomi, 2000).

The population for this study consisted of 5 OBD system technicians and all 58 teachers of Motor Vehicle Mechanics' Work in 40 NBTE-accredited technical colleges in South Eastern States of Nigeria. The States are Abia, Anambra, Ebonyi, Enugu, and Imo States. The States house several vehicle servicing workshops. In addition to that, Enugu State houses a functional automobile maintenance and assembly plant. These areas offer a desirable number of subjects who responded to the instrument of the data collection of this study. The names of the accredited technical colleges were got from the various states' Ministries of Education.

The instrument for data collection for this study was structured questionnaire; consisting of 14 items which sought information on the actuators of OBDS improvement competencies needed by the teachers. The questionnaire has two columns of needed category and performance category as follows: Very Highly Needed (VHN) 5, Highly Needed (HN) 4, Averagely Needed (AN) 3, Slightly Needed (SN) 2, and Not Needed (NN) 1. The performance category also has a five point scale of: Very High Performance (VHP) 5, High Performance (HP) 4, Average Performance (AP) 3, Low Performance (LP) 2, and Very Low Performance (VLP) 1. The questionnaire was face validated by three experts. Cronbach Alpha method was used to determine the internal consistency of the instrument, which give a coefficient index of 0.93 .

\section{Results}

The results are presented according to the research questions and hypothesis that guided the study.

\section{Research Questions 1 and 2}

Table 1: Mean Responses of Teachers of Motor Vehicle Mechanics' Work on Competences in Actuators of OnBoard Diagnostic System

\begin{tabular}{|c|c|c|c|c|c|}
\hline $\mathrm{S} / \mathrm{N}$ & Item statement & $\overline{\mathrm{xN}}$ & $\overline{x P}$ & $\overline{\mathrm{x}} \mathrm{N}-\overline{\mathrm{xP}}$ & Remark \\
\hline 1. & Identify a solenoid operated actuator & 4.44 & 3.70 & 0.74 & $\mathrm{RIN}^{*}$ \\
\hline 2. & Identify an electric motor operated actuator & 4.42 & 3.52 & 0.90 & RIN \\
\hline 3. & Differentiate between solenoid and electric motor operated actuator & 4.40 & 3.34 & 1.06 & RIN \\
\hline 4. & Identify single point petrol injector & 4.96 & 4.94 & 0.02 & RIN \\
\hline 5. & Identify multi point petrol injector & 4.96 & 3.90 & 1.06 & RIN \\
\hline 6. & Differentiate between single and multi point injector & 4.98 & 3.70 & 1.28 & RIN \\
\hline 7. & Test a petrol engine for actuators that are in good condition & 4.98 & 1.36 & 3.62 & RIN \\
\hline 8. & Maintain actuator and injector & 4.99 & 1.12 & 3.87 & RIN \\
\hline 9. & Read the misfire code problems of the injector & 4.86 & 2.46 & 2.40 & RIN \\
\hline 10. & Identify negative trigger or ground controlled injector & 4.21 & 1.00 & 3.21 & RIN \\
\hline 11. & Identify positive or battery voltage trigger injector & 4.21 & 1.00 & 3.21 & RIN \\
\hline
\end{tabular}


Competences In On-Board Diagnostic Actuators For Effective Teaching Of Petrol Engine...

\begin{tabular}{|l|l|l|l|l|l|}
\hline 12. & Identify the saturation injector driver & 4.47 & 1.98 & 2.49 & RIN \\
\hline 13. & Identify the peak-and-hold injector driver & 4.63 & 1.25 & 3.38 & RIN \\
\hline 14. & Switch the injector on and off using the drivers & 4.84 & 1.12 & 3.72 & RIN \\
\hline
\end{tabular}

*Required and Improvement Needed

Data shown on table 1indicate that all the fourteen (14) items are required and improvement are needed on them by the teachers. Competencies are required in the use of actuators of on-board diagnostic system for effective teaching of Petrol Engine Maintenance in the following;

1. Identify a solenoid operated actuator

2. Identify an electric motor operated actuator

3. differentiate between solenoid and electric motor operated actuator

4. Identify single point petrol injector

5. Identify multi point petrol injector

6. Differentiate between single and multi point injector

7. Test a petrol engine for actuators that are in good condition

8. Maintain actuator and injector

9. Read the misfire code problems of the injector

10. Identify negative trigger or ground controlled injector

11. Identify positive or battery voltage trigger injector

12. Identify the saturation injector driver

13. Identify the peak-and-hold injector driver

14. Switch the injector on and off using the drivers

\section{Hypothesis}

$\mathrm{Ho}_{1}$ : There is no significant difference in the mean ratings of the responses of the teachers, based on their experiences, on the competencies needed in the use of actuators of on-board diagnostic system for effective teaching of petrol engine maintenance.

Table 2: ANOVA of the Responses of the Teachers, based on their Experiences, on the Competencies Needed in the Use of Output Devices of On-Board Diagnostic System for Effective Teaching of Petrol Engine

$$
\text { Maintenance }
$$

n- $16(0-5$ years $) ; 8(6-10$ years $) ; 9(11-15$ years $) ; 6(16-20$ years $) ; 7(21-25$ years $) ; 9(26-30$ years $)$; and $3(31-35)$

\begin{tabular}{|l|l|l|l|l|l|}
\hline Source of Variance & Sum of Squares & Df & Mean Square & f-Cal & f-Tab \\
\hline Between Groups & 1.0287 & 6 & 0.171 & 0.810 & 2.32 \\
Within Groups & & & & & \\
Total & 9.073 & 43 & 0.211 & & \\
\hline
\end{tabular}

$\mathrm{n}=$ number of responded

The result in the table 2 indicated that calculated value is equal to 0.810 which was less than the table value of 2.32 at 0.05 levels of significance and degree of freedom of 6 and 43 . This revealed that there was no significance (NS) difference in the mean ratings of responses of the teachers, based on their experiences, on the competencies needed in the use of output devices of on-board diagnostic system for effective teaching of petrol engine maintenance. The null hypothesis $\left(\mathrm{Ho}_{1}\right)$ is therefore not rejected.

\section{Discussion}

The findings regarding the competencies required and improvement needs of the teachers in the use of actuators of on-board diagnostic system for effective teaching of petrol engine maintenance, as presented in table 1 showed that all the fourteen (14) items are required and improvement is needed in all of them. This signifies that teachers should be trained in competencies involved in actuators. The injector, as one of the actuators, receives instruction from the input devices through the Engine Control Unit. Its importance in mechatronics lies in the fact that the instruction for optimization if not carried out is useless. Therefore Don (2008) stated that fuel efficiency and reduction of carbon dioxide (one of the green house gases) can only be achieved through the right timing of the injectors to the combustion chamber.

The teacher, when he is trained in on-board diagnostic system, would impart the right information to the student who in turn would use it to maintain vehicles that use on-board diagnostic system. One of the vocational principle states that what is use to train should be a replica of what should be used in the industry. Therefore when there is innovation in the industry (automobile), the innovation should get to the trainers (teachers) who in turn should transfer the information to the trainee (students) that would complete the cycle by working in the innovated industry. 


\section{Implications of the Study's Findings}

The educational implications of this study are:

- The teachers when improved in the use of on-board diagnostic system would teach Petrol Engine Maintenance effectively.

- When the teachers are improved, their students will be equipped with the skills that are required to maintain the vehicles that use on-board diagnostic system.

- When the students graduate, they would become economically self-reliant craftsmen.

- There is no significance difference in the mean ratings of the responses of the teachers of various years of teaching experiences in competences needed in on-board diagnostic sensors for effective teaching of Petrol Engine Maintenance in technical colleges in Nigeria.

\section{Conclusion And Recommendation}

Based on the findings of this study, it is concluded that teachers of Motor Vehicle Mechanics' Work in Nigeria need improvement in on-board diagnostic system for effective teaching of Petrol Engine Maintenance. There is therefore an urgent need to improve these teachers. This is necessary in order to teach the students who will service the recent petrol engine vehicles that use on-board diagnostic system effectively.

Based on the findings of the study, the following recommendations are made:

1. There should be in-service training in on-board diagnostic system for the teachers of Motor Vehicle Mechanics' Work. The administrators should organise workshops where these teachers could be trained by experts of on-board diagnostic system. They could better still be given scholarship to further their education in their related area; that is, study leave with pay.

2. New technological developments having implications for automobile such as in on-board diagnostic system, should be integrated into the skills contents and learning contents of the curriculum of technical education programme. Production of craftsmen on motor vehicle mechanics by technical colleges should be based on the need of automobile industries; consequently, the curriculum contents should be directly related to what industries and business need to make graduates easily work in the industries. These called for curriculum contents that are directly related to the new technological development to be integrated into technical colleges' curriculum.

However, the integration of automobile technological developments into Nigeria technical college Motor Vehicle Mechanics' Work curriculum will involve combining the theoretical and practical contents of automobile technological development into the existing technical colleges Motor Vehicle Mechanics' Work curriculum.

3. There should be an advocacy on the importance of in-service training and that of including on-board diagnostic system to the curriculum of Motor Vehicle Mechanics' Work. The curriculum planners and education policy makers should be made to understand the innovations of automobile which include onboard diagnostic system. Various sensitization programmes should be organised through the various media, academic discourse such as in conferences.

4. Vehicles that use on-board diagnostic system should be used in teaching the students. Various technical colleges should be advised to buy vehicles which they could afford, (either new ones or fairly used ones), but the ones which have on-board diagnostic system. Government and other relevant bodies such as the Parent Teacher Association could still be invited to donate such vehicles, maybe after the advocacy.

[1]. Borich, G. D. (1980). A needs assessment model for conducting follow-up studies. Journal of Teacher Education, 31 (3). Retrieved from www.joe.org/joe/2011april/tt8.php

[2]. Daily Trust (Oct. 5, 2009). Fear of retirement

[3]. Don, D. (2008). Actron pocketscan obd ii code reader. Retrieved from www.obd-onboarddiagnostics.com/clinic.htm.

[4]. NBTE (2009). National technical certificate and advanced national technical certificate curriculum and module specification for Motor Vehicle Mechanics Work. Kaduna, NBTE

[5]. Nice, K. (2001). How car computers work. Retrieved from http://www.Howstuffworks.com.

[6]. Odigiri, A.M (2004) Technological innovations in automobiles and curriculum revision needs for Motor Vehicle Mechanics Work programmes in Nigerian technical colleges. Unpublished M.Ed. Thesis, Department of Vocational Teacher Education, University of Nigeria, Nsukka.

[7]. Smith, C. (2006). "Monitoring fuel consumption on your vehicle in "Real-Time"'. Retrieved from http://www.windmill.co.uk/obdii.pdf. 